\title{
High genetic variability revealed by allozymic loci in the narrow endemic fern Polystichum otomasui (Dryopteridaceae)
}

\author{
MASAYUKI MAKI* \& YU-J I ASADA \\ Department of Biology, Fukuoka University of Education, 729-1 Akama, Munakata, Fukuoka, 811-41 J apan
}

\begin{abstract}
Genetic variability was examined at 16 putative allozymic loci in the narrow endemic fern Polystichum otomasui. Although this species is distributed in only a few valleys within an approximately $10 \mathrm{~km} \times 6 \mathrm{~km}$ area on the Kyusyu Island of Japan, there are a relatively large number of individuals in this area. The percentage of polymorphic loci $(P)$, the number of alleles per locus $(A)$, the observed heterozygosity $\left(H_{\mathrm{O}}\right)$ and the expected heterozygosity $\left(H_{\mathrm{E}}\right)$ were $61.9,1.93,0.166$ and 0.177 , respectively, at the population level, and $P, A$ and $H_{\mathrm{E}}$ were 81.3, 2.69 and 0.199, respectively, at the species level, indicating that $P$. otomasui has extremely high allozymic variation for a fern species. The $G_{\text {Sт }}$ value among the 10 populations examined within the range was 0.108 , suggesting that the interpopulation gene flow is high enough to impede genetic structuring. The mating system estimates, Wright's fixation index and the intragametophytic selfing rate, indicate that the species is outcrossing. High genetic variability, in spite of narrowness of the distribution, may have resulted from a recent rapid decline in the population and/or the large effective population size resulting from the extensive gene flow among the populations.
\end{abstract}

Keywords: allozyme, fern, gene flow, genetic variability, narrow endemic, Polystichum otomasui.

\section{Introduction}

Genetic variation in a population is considered to have evolutionary potential. Therefore, the level of genetic variation and the factors influencing genetic variability have been a primary concern of evolutionary geneticists. The width of distribution is one of the major factors correlated with the genetic variability of plant populations (Karron, 1987; Hamrick \& Godt, 1990). Geographically restricted species tend to have lower levels of genetic variation than their more widespread congeners (e.g. ShermanBroyles et al., 1992; Purdy \& Bayer, 1996). Some studies have reported no variation in allozymic loci in narrow endemic species (e.g. Waller et al., 1987; Soltis et al., 1992). On the other hand, a few studies have shown abundant genetic variation even in geographically restricted species (Ranker, 1994; Lewis \& Crawford, 1995).

The distribution of a species is determined mainly by its adaptability to the habitat, barriers to dispersal and historical events (Cox \& Moore, 1993). In

*Correspondence. E-mail: makim@fukuoka-edu.ac.jp homosporous ferns, the ability to disperse is believed to be higher than for most of the seed plants because of the aerodynamic properties of their spores (Tryon, 1970; Soltis \& Soltis, 1990a). In addition, a homosporous fern gametophyte may have the potential for self-fertilization because of its hermaphroditism, although most of the diploid homosporous fern species are highly outcrossing (Soltis \& Soltis, 1990b). Capacity for self-fertilization seems to facilitate long-distance establishment of populations (Baker, 1955). Thus, if a fern species does not require a specific habitat, such as a high mountain area, salt marsh or a rocky site, the distribution of the species is expected to be relatively wide. Otherwise, the distribution may reflect the evolutionary history of the species.

Polystichum otomasui Sa. Kurata (Dryopteridaceae) is a perennial fern, which is distributed in an extremely restricted area of Japan (Kurata, 1963). This species occurs in the understorey of temperate evergreen forest or artificial coniferous forest and does not appear to require specific microhabitat conditions. 
In this study, we have used enzyme electrophoresis to examine genetic diversity at both the population and the species level, genetic differentiation among the populations and the mating system of $P$. otomasui.

\section{Materials and methods}

\section{Study organism}

Polystichum otomasui is distributed in only a few valleys within an approximately $10 \times 6 \mathrm{~km}$ area on the Kyushu Islands of Japan (Fig. 1). The species is found in the moist understorey of temperate evergreen forests mainly composed of Machilus japonica and Castanopsis cuspidata and artificial forests of Sugi (Cryptomeria japonica). The number of individuals of $P$. otomasui in the valleys is relatively large. Curiously, however, $P$. otomasui has not been found outside this narrow area, although similar evergreen and artificial forests are common.

The chromosome number of $P$. otomasui is $2 n=82$, which is considered to be diploid (Iwatsuki, 1995). Putative natural hybridizations between $P$. otomasui and five tetraploid congeneric species (P. makinoi, $P$. ovato-paleaceum, $P$. polybrepharum, $P$. pseudo-makinoi and $P$. tagawanum var. tagawanum) have been reported (Iwatsuki, 1995). Unfortunately, at present, phylogenetic relationships between $P$. otomasui and these five tetraploid congeners are unknown.

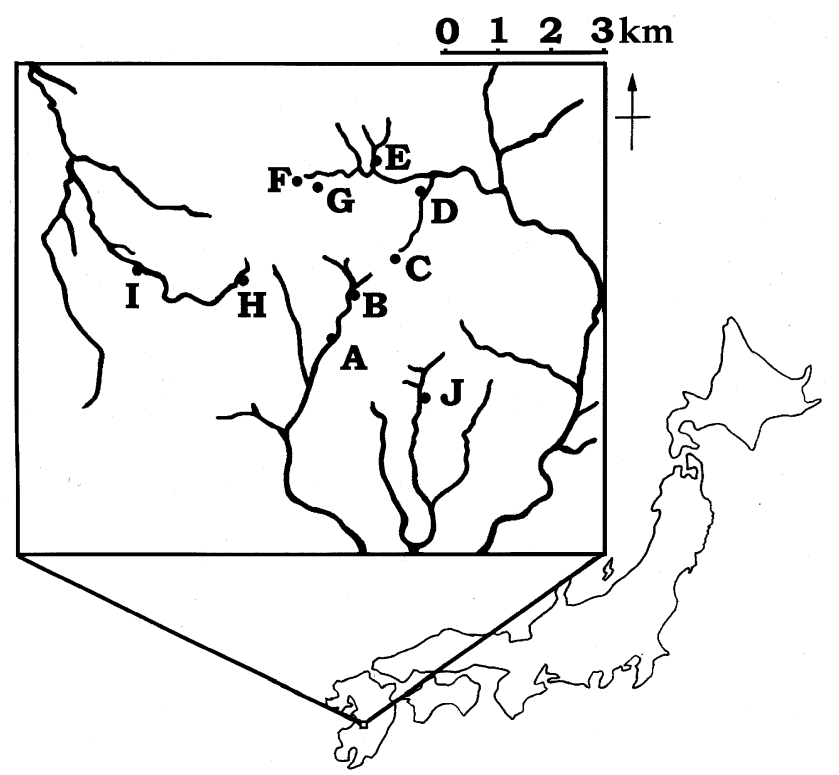

Fig. 1 Distribution of the examined populations of Polystichum otomasui.

(C) The Genetical Society of Great Britain, Heredity, 80, 604-610.

\section{Sampling}

A portion of the young leaf blade was sampled from 24-35 P. otomasui individuals from each of $10 \mathrm{popu}-$ lations in the distribution area (Fig. 1). The samples were placed on ice and transported to the laboratory of Fukuoka University of Education, refrigerating the samples for several days until the electrophoresis was carried out.

\section{Enzyme electrophoresis}

One hundred milligrams of the leaf blade was homogenized in $1000 \mu \mathrm{L}$ of extract buffer made up of $93 \mathrm{~mm}$ Tris- $\mathrm{HCl}$ (pH. 8.0), 23.4\% glycerol, $0.6 \%$ $(\mathrm{v} / \mathrm{v})$ Tween 80, $2.8 \mathrm{~mm}$ EDTA, $2.3 \mathrm{~mm}$ NAD, $1.6 \mathrm{~mm}$ NADP, $11 \mathrm{~mm}$ dithiothreitol, $0.5 \%$ 2-mercaptoethanol, $0.08 \%$ bovine serum albumin and $7 \%$ polyvinylpolypyrrolidone modified from Tsumura et al. (1990). The homogenates were centrifuged at $20000 \mathrm{~g}$ for $10 \mathrm{~min}$ at $4^{\circ} \mathrm{C}$. Ten microlitres of the resulting supernatant was used for electrophoresis for each enzyme. Polyacrylamide vertical slab gel electrophoresis was carried out according to the procedure of Tsumura et al. (1990); preliminary studies using both starch and polyacrylamide gels yielded similar results, but some loci resolved better with polyacrylamide. The following 13 enzyme systems were examined: asparate aminotransferase (AAT; EC 2.6.1.1), fructose 1,6-diphosphatase (F1,6DP; EC 3.1.3.11), glucose 6-phosphate dehydrogenase (G6PDH; EC 1.1.1.49), glucose6-phosphate isomerase (GPI; EC 5.3.1.9), glutamate dehydrogenase (GDH; EC 1.4.1.2), glycerate dehydrogenase (G2DH; EC 1.1.1.29), hexokinase (HK; EC 2.7.1.1), leucine aminopeptidase (LAP; EC 3.4.11.1), menadione reductase (MR; 1.6.99.-), phosphoglucomutase (PGM; EC 5.4.2.2), 6-phosphogluconate dehydrogenase (6PGDH; EC 1.1.1.44), shikimate dehydrogenase (SkDH; EC 1.1.1.25) and triose-phosphate isomerase (TPI; EC 5.3.1.1). Staining protocols followed Tsumura et al. (1990), except F1,6DP and G6PDH, for which we followed Soltis et al. (1983).

\section{Statistical analysis}

Allele frequencies in each population of $P$. otomasui were calculated for the loci encoding the 13 enzyme systems. The following indices were used to quantify the level of genetic diversity within each population: the proportion of polymorphic loci $(P)$ at the $99 \%$ criterion; the number of alleles per locus $(A)$; observed heterozygosity $\left(H_{\mathrm{O}}\right)$; and expected heterozygosity $\left(H_{\mathrm{E}}\right)$. All these indices except $H_{\mathrm{O}}$ were also 
calculated at the species level. Following Hamrick \& Godt (1990), we treated the loci polymorphic in at least one population as polymorphic at the species level. Genetic diversity of $P$. otomasui at the population and the species levels was compared with data compiled from studies examining allozyme diversity of diploid homosporous ferns (references cited in Soltis \& Soltis, 1990a; Werth et al., 1985; Soltis \& Soltis, 1987, Haufler et al., 1990; Soltis et al., 1991; Werth, 1991; Ranker, 1992a,b, 1994; Li \& Haufler, 1994; Korpelainen \& Kolkkala, 1996). At the species level, we compiled data from the studies examining two or more populations per species, and the population-level data also included those studies examining only one population per species. For some species and/or populations, the genetic diversity indices were calculated using allele frequency tables from the literature.

Genetic diversity among populations of $P$. otomasui was estimated by Nei's gene diversity statistics (Nei, 1987) for all polymorphic loci. Values for genetic identities $(I)$ and standard genetic distance $(D)(\mathrm{Nei}, 1987)$ were also computed for each pairwise comparison among the 10 populations of $P$. otomasui.

The mating system of $P$. otomasui was examined by two estimators: Wright's (1951) fixation index and the intragametophytic selfing rate. For each polymorphic locus at which the frequency of the most common allele did not exceed 0.95, a fixation index $(F)$ was estimated as $F=1-\left(n_{\mathrm{O}} / n_{\mathrm{E}}\right)$, where $n_{\mathrm{O}}$ is the observed number of heterozygotes and $n_{\mathrm{E}}$ is the expected number of heterozygotes at Hardy-Weinberg equilibrium. Deviations of $F$ from zero were tested using $\chi^{2}$-statistics (Li \& Horvitz, 1953). Intragametophytic selfing rates were estimated for each population using genotype frequency data at the polymorphic loci. Holsinger's (1987) method was applied to calculate the bootstrap estimates and confidence intervals.

\section{Results}

\section{Genetic diversity at the population level}

A total of 16 loci encoding 13 enzyme systems were resolved: Aat, F1,6dp, G6pdh, Gdh, Gpi-2, G2dh, Hk, Lap, Mnr, Pgm-1, Pgm-2, 6pgdh-1, 6pgdh-2, Skdh, Tpi-1 and Tpi-2. Because Gpi-1 was not consistently scored, we excluded this locus from further analyses. Among the 16 loci, Aat, F1,6dp and G6pdh were monomorphic in all populations and the other 13 loci were polymorphic in at least one of the populations examined.
Values for all genetic diversity indices $\left(P, A, H_{\mathrm{O}}\right.$ and $\left.H_{\mathrm{E}}\right)$ at the population level in $P$. otomasui were much higher than the mean values for diploid homosporous ferns (Table 1). Values for three indices $(P$, $A$ and $H_{\mathrm{E}}$ ) in $P$. otomasui were also even higher than the mean values for widespread seed plants (Table $1)$.

\section{Genetic diversity at the species level}

Values for the genetic diversity indices $(P, A$ and $\left.H_{\mathrm{E}}\right)$ at the species level in $P$. otomasui were much higher than the mean values for diploid homosporous ferns (Table 2). Values for two of the indices $(P$ and $A$ ) in $P$. otomasui were also higher than the mean values for those in widespread seed plants (Table 2). The expected heterozygosity $\left(H_{\mathrm{E}}\right)$ in $P$. otomasui was similar to the mean value for widespread seed plants.

\section{Genetic differentiation among populations}

The average coefficient of gene differentiation $\left(G_{\mathrm{ST}}\right)$ across all the polymorphic loci was low (0.108) (Table 3). This value was similar to that of windpollinated outcrossing seed plants $\left(G_{\mathrm{ST}}=0.099\right)$ (Hamrick \& Godt, 1990). Means of Nei's genetic identity and standard genetic distance for each pairwise comparison of all 10 populations were 0.971 (range 0.929-0.989) and 0.030 (range 0.008-0.068), respectively, also indicating low genetic differentiation among the populations.

\section{Mating system}

Fixation indices $(F)$ were tested for the significance of deviations from zero in 78 cases in $P$. otomasui (Table 4). Of those $78 F$-values, 10 were significantly positive, indicating a deficiency of heterozygotes, and only two were significantly negative, indicating an excess of heterozygotes. The mean $F$-values for each population were nearly zero, indicating that, on the whole, the populations are at Hardy-Weinberg equilibrium. The rates of intragametophytic selfing were nearly zero in all populations (Table 5), as expected from the fixation indices.

\section{Discussion}

The genetic variability in $P$. otomasui is higher than expected given the tendency of geographically restricted species to have low levels of genetic variation (Karron, 1987; Hamrick \& Godt, 1990; Soltis \& Soltis, 1991). As in seed plants, geographical distri-

(C) The Genetical Society of Great Britain, Heredity, 80, 604-610. 
Table 1 The proportion of polymorphic loci $(P)$, the number of alleles per locus $(A)$, observed heterozygosity $\left(H_{\mathrm{O}}\right)$ and expected heterozygosity $\left(H_{\mathrm{E}}\right)$ at 16 loci for examined populations of Polystichum otomasui and the genetic diversity at the population level of the diploid homosporous ferns and the widespread seed plants

\begin{tabular}{lllll}
\hline Population & \multicolumn{2}{c}{$P$} & \multicolumn{1}{c}{$A$} & $H_{\mathrm{O}}$ \\
\hline $\mathrm{A}$ & 62.5 & 1.94 & 0.167 & 0.171 \\
$\mathrm{~B}$ & 62.5 & 2.00 & 0.154 & 0.161 \\
$\mathrm{C}$ & 56.3 & 2.00 & 0.231 & 0.220 \\
$\mathrm{D}$ & 68.8 & 1.94 & 0.155 & 0.173 \\
$\mathrm{E}$ & 62.5 & 2.06 & 0.180 & 0.184 \\
$\mathrm{~F}$ & 62.5 & 2.06 & 0.133 & 0.107 \\
$\mathrm{G}$ & 62.5 & 2.00 & 0.149 & 0.187 \\
$\mathrm{H}$ & 56.3 & 1.81 & 0.173 & 0.230 \\
$\mathrm{I}$ & 62.5 & 1.81 & 0.168 & 0.180 \\
$\mathrm{~J}$ & 62.5 & 1.81 & 0.146 & 0.189 \\
Mean & 61.9 & 1.93 & 0.166 & 0.177 \\
Diploid homosporous & $31.5^{\mathrm{A}}(3.3)$ & $1.52^{\mathrm{B}}(0.07)$ & $0.136^{\mathrm{C}}(0.027)$ & $0.110^{\mathrm{A}}(0.014)$ \\
$\quad$ fern* & & & & \\
Widespread seed & $43.0(3.3)$ & $1.72(0.07)$ & - & $0.159(0.013)$ \\
$\quad$ plants $\dagger$ & & & & \\
\hline
\end{tabular}

Values in parentheses indicate the standard errors.

*A, B and C are from the data available for 32,30 and 23 species, respectively (see text).

$\dagger$ According to Hamrick \& Godt (1990).

bution is one of the major factors determining genetic diversity in fern species (Soltis \& Soltis, 1990a).

Soltis \& Soltis (1991) examined the effects of species range on the genetic diversity of five North American diploid Polystichum species. Two geographically restricted species ( $P$. dudley and $P$. lemmonii) have maintained a much lower genetic diversity than three more widespread species $(P$. acrostichoides, $P$. imbricans and $P$. munitum). The genetic diversity of $P$. otomasui is much higher than these congeneric North American species, even though the distribution of $P$. otomasui is extremely restricted.

A few studies have shown that geographically restricted species maintain a higher genetic diversity than more widespread congeners. Ranker (1994) has shown that the very rare fern Adenophorus periens has much higher levels of allozymic variation than two other more widespread congeners. He hypothe-

Table 2 The proportion of polymorphic loci $(P)$, the number of alleles per locus $(A)$ and expected heterozygosity $\left(H_{\mathrm{E}}\right)$ at 16 loci for Polystichum otomasui and the genetic diversity at the species level of the diploid homosporous ferns and the widespread seed plants

\begin{tabular}{llll}
\hline & \multicolumn{1}{c}{$P$} & \multicolumn{1}{c}{$A$} & \multicolumn{1}{c}{$H_{\mathrm{E}}$} \\
\hline P. otomasui & 81.3 & 2.69 & 0.199 \\
Diploid homosporous fern* & $31.3^{\mathrm{A}}(4.2)$ & $1.52^{\mathrm{B}}(0.24)$ & $0.150^{\mathrm{B}}(0.025)$ \\
Widespread seed plants $\dagger^{+}$ & $58.9(3.1)$ & $2.29(0.16)$ & $0.202(0.015)$ \\
\hline
\end{tabular}

Values in parentheses indicate the standard errors.

*A and B are from the data available for 19 and eight species, respectively (see text).

$\dagger$ According to Hamrick \& Godt (1990). 
sized that, although the historical factors leading to the high genetic variability of the species are somewhat obscure, the outcrossed mating system and somatic mutations may have played a key role. In the population genetic study on 11 species of Polygonella, Lewis \& Crawford (1995) found that the two most widespread species have a reduced withinpopulation gene diversity with respect to their narrowly endemic congeners. He explained that these unexpected results are caused by high levels of self-fertilization for the widespread species and a large-scale migration during Pleistocene glaciation.

Table 3 Gene diversity for individual loci and the mean values for all polymorphic loci in Polystichum otomasui

\begin{tabular}{lccc}
\hline & $H_{\mathrm{S}}$ & $H_{\mathrm{T}}$ & $G_{\mathrm{ST}}$ \\
\hline Gpi-2 & 0.149 & 0.157 & 0.052 \\
Gdh & 0.253 & 0.273 & 0.075 \\
G2dh & 0.427 & 0.499 & 0.144 \\
Hk & 0.210 & 0.279 & 0.247 \\
Lap & 0.676 & 0.733 & 0.077 \\
Mnr & 0.134 & 0.145 & 0.079 \\
Pgm-1 & 0.374 & 0.319 & 0.141 \\
Pgm-2 & 0.099 & 0.130 & 0.235 \\
6pgdh-1 & 0.046 & 0.048 & 0.039 \\
6pgdh-2 & 0.121 & 0.133 & 0.092 \\
Skdh & 0.026 & 0.028 & 0.059 \\
Tpi-1 & 0.425 & 0.440 & 0.035 \\
Tpi-2 & 0.043 & 0.047 & 0.086 \\
Mean & 0.180 & 0.202 & 0.108 \\
\hline
\end{tabular}

As with the above species, some explanations are possible for the high genetic variability of $P$. otomasui. First, P. otomasui may have a large effective population size at the species level, irrespective of its extremely narrow distribution. Genetic differentiation among the populations was very low, suggesting extensive gene flow among them. In the infinite island model, $G_{\mathrm{ST}} \approx 1 /(1+4 N m)$, where $G_{\mathrm{ST}}$ and $N m$ are the coefficient of gene differentiation and the number of migrants per generation respectively (Slatkin \& Barton, 1989). When $N m>1$, genetic differentiation among populations as a result of genetic drift is highly impeded (Hartl \& Clarke, 1989). In this study, $G_{\mathrm{ST}}$ was 0.108 among the 10 populations, giving $N m \approx 2.072$, which is very high. Although the distribution of $P$. otomasui is extremely restricted, the individuals occur continuously in the valleys, effectively resulting in the formation of a single integrated population. In addition, mating systems profoundly influence the effective population size in plants. Theoretical considerations show that selfing reduces the effective size of subpopulations (Tachida \& Yoshimaru, 1996). The outcrossing habit of $P$. otomasui may play a key role in the maintenance of genetic diversity of the species.

Secondly, the current high level of genetic diversity may reflect the former large population size of the species. Recent rapid decline of the populations is possible. Although the explicit causes are obscure at present, some ecological causes may be speculated on for the rapid population decline. Competition between $P$. otomasui and the tetraploid congeners in the same habitat may have caused the

Table 4 Fixation indices for individual loci and the mean values for all polymorphic loci for each population of Polystichum otomasui

\begin{tabular}{lcccccccccc}
\hline & $\mathrm{A}$ & $\mathrm{B}$ & $\mathrm{C}$ & $\mathrm{D}$ & $\mathrm{E}$ & $\mathrm{F}$ & $\mathrm{G}$ & $\mathrm{H}$ & $\mathrm{I}$ & $\mathrm{J}$ \\
\hline Gdh & - & - & 0.280 & -0.091 & 0.167 & 0.252 & 0.139 & -0.174 & 0.267 & -0.210 \\
Gpi-2 & 0.345 & - & 0.156 & - & 0.191 & -0.156 & 0.191 & -0.071 & - & - \\
G2dh & $-0.394^{*}$ & 0.190 & -0.222 & -0.167 & -0.292 & 0.105 & 0.083 & -0.068 & -0.142 & -0.244 \\
Hk & - & - & -0.069 & -0.176 & -0.094 & - & - & -0.333 & -0.087 & -0.142 \\
Lap & $0.414^{*}$ & $0.380^{*}$ & $0.600^{* *}$ & $0.602^{* *}$ & $0.400^{*}$ & 0.214 & 0.200 & $0.399^{*}$ & $0.354^{*}$ & 0.371 \\
Mnr & - & - & -0.071 & -0.071 & - & - & - & 0.108 & 0.319 & 0.330 \\
Pgm-1 & 0.096 & 0.111 & 0.028 & 0.200 & 0.090 & -0.077 & - & - & - & -0.043 \\
Pgm-2 & $0.270^{*}$ & - & -0.612 & - & -0.098 & - & - & - & - & - \\
6pgdh-1 & - & - & - & - & -0.055 & - & -0.055 & - & 0.267 & - \\
Gpgdh-2 & - & $0.352^{*}$ & - & 0.130 & - & -0.052 & -0.016 & -0.052 & -0.022 & - \\
Skdh & - & - & - & - & -0.087 & - & - & - & -0.065 & - \\
Tpi-1 & -0.232 & $-0.482^{* *}$ & -0.199 & 0.333 & -0.033 & 0.314 & -0.416 & -0.155 & -0.095 & -0.008 \\
Tpi-2 & - & 0.059 & - & - & - & - & - & - & - & $0.498^{*}$ \\
Mean & 0.100 & 0.082 & -0.047 & 0.058 & 0.019 & 0.086 & 0.035 & 0.043 & 0.066 & 0.069 \\
\hline
\end{tabular}

${ }^{*} P<0.05 ;{ }^{* *} P<0.01$. 
Table 5 Estimates of intragametophytic selfing rates for Polystichum otomasui

\begin{tabular}{lcc}
\hline Population & $\begin{array}{c}\text { Bootstrap-1000 } \\
\text { estimate }\end{array}$ & $\begin{array}{c}95 \% \text { confidence } \\
\text { interval }\end{array}$ \\
\hline A & 0.080 & $0.000-0.248$ \\
B & 0.085 & $0.000-0.254$ \\
C & 0.000 & $0.000-0.097$ \\
D & 0.039 & $0.000-0.194$ \\
E & 0.000 & $0.000-0.111$ \\
F & 0.105 & $0.000-0.260$ \\
G & 0.094 & $0.000-0.248$ \\
H & 0.000 & $0.000-0.115$ \\
I & 0.049 & $0.000-0.180$ \\
J & 0.063 & $0.000-0.237$ \\
\hline
\end{tabular}

population decline of the former species. In the habitat of $P$. otomasui, several tetraploid Polystichum species frequently co-occur. Polyploid species are often more vigorous than their diploid congeners (Levin, 1983). In fact, in contrast to P. otomasui, the tetraploid congeners are widespread in Japan (Iwatsuki, 1995). In addition, $P$. otomasui often hybridizes with these tetraploid species, especially with $P$. tagawanum var. tagawanum, generating sterile but more vigorous hybrid individuals (Kurata, 1963), which may outcompete $P$. otomasui. At several sites, individuals generated by the hybridization of $P$. otomasui and $P$. tagawanum var. tagawanum are more abundant than the parent species (M. Maki, pers. obs.). As a result of perenniality, the hybrids will occupy the same habitat for a long time, reducing the opportunity for the regeneration of $P$. otomasui.

Another possible cause of the population decline in $P$. otomasui is climate change. In the past, $P$. otomasui may have been more widely distributed but is now confined to the current restricted area following a recent climate change. Considering the dispersal ability of its spores, however, P. otomasui should extend its distribution to adjacent areas, which appear to be similar environments. Therefore, it is difficult to explain the narrow distribution of the species solely by climate change. Although it is difficult to examine the effects of historical events on the present distribution of a plant species, we are now testing the hypothesis that both competition and natural hybridization with the congeneric tetraploids influence the population dynamics of $P$. otomasui.

Polystichum otomasui is not listed in the Red Data Book of Japanese plants (JPRDBC, 1989), probably because relatively large numbers of individuals are found in the area. From the point of view of conservation genetics, an urgent conservation plan does not appear to be necessary for $P$. otomasui However, the natural evergreen forests in this area are now quickly being cut for artificial forest. Moreover, the artificial forests are also being felled for lumber production. Because $P$. otomasui yellows and wilts under direct exposure to the sun (M. Maki, pers. obs.), it is necessary to keep part of the forests in the area as at least a temporary refuge.

\section{Acknow ledgements}

We thank Dr Y. Watano for the computer program and Messrs T. Minamitani, S. Oiki and H. Morita for sampling materials. This work was partly supported by a grant-in-aid from the Ministry of Education, Science and Culture, Japan (no. 07304081) and the Global Environment Research Fund (F-1) from the Japan Environment Agency to M.M.

\section{References}

BAKER, H. G. 1955. Self-compatibility and establishment after 'long-distance' dispersal. Evolution, 9, 347-349.

COX, C. B. AND MOORE, P. D. 1993. Biogeography. Blackwell Scientific Publications, Oxford.

HAMRICK, J. L. AND GODT, M. J. 1990. Allozyme diversity in plant species. In: Brown, A. H. D., Clegg, M. T., Kahler, A. L. and Weir, B. S. (eds) Plant Population Genetics, Breeding, and Genetic Resources, pp. 43-63. Sinauer, Sunderland, MA.

HARTl, D. L. AND Clark, A. G. 1989. Principles of Population Genetics, 2nd edn. Sinauer, Sunderland, MA.

HAUfler, C. H., WINDHAM, M. D. AND RANKER, T. A. 1990. Biosystematic analysis of the Cystopteris tennesseensis (Dryopteridaceae) complex. Ann. Mo. Bot. Gard., 77, 314-329.

HOLSINGER, K. E. 1987. Gametophytic self-fertilization in homosporous plants: development, evaluation, and application of a statistical method for evaluating its importance. Am. J. Bot., 74, 1173-1183.

IWAtsuki, K. 1995. Drypoteridaceae. 3. Polystichum. In: Iwatsuki, K., Kato, M. and Yamazaki, T. (eds) Flora of Japan, vol. I, Pteridophyte and Gymospermae, pp. 124-137. Kodansya, Tokyo.

JPRDBC (JAPAN PLANT RED DATA BOOK COMMitTEE) 1989. Japanese Red Data Book of Plants. Nature Conservation Society of Japan, Tokyo.

KARron, J. D. 1987. A comparison of levels of genetic polymorphism and self-incompatibility in geographically restricted and widespread plant congeners. Evol. Ecol., 1, 47-58.

KORPElAinen, H. AND KOLKKALA, M. 1996. Genetic diversity and population structure in the outcrossing popula- 
tions of Equisetum arvense and $E$. hyemale (Equisetaceae). Am. J. Bot., 83, 58-62.

KURATA, s. 1963. Notes on Japanese Ferns (32). J. Geobot., 12, 66-69 (in Japanese with English summary).

LEVIN, D. A. 1983. Polyploidy and novelty in flowering plants. Am. Nat., 122, 1-25.

LEWIS, P. O. AND CRAWFORD, D. J. 1995. Pleistocene refugium endemics exhibit greater allozyme diversity than widespread congeners in the genus Polygonella (Polygonaceae). Am. J. Bot., 82, 141-149.

LI, C. C. AND HORVITZ, D. G. 1953. Some methods of estimating the inbreeding coefficient. Am. J. Hum. Genet., 5, 107-117.

LI, J. AND HAUfler, C. H. 1994. Phylogeny, biogeography, and population biology of Osmunda species: insight from isozymes. Am. Fern J., 84, 105-114.

NEI, M. 1987. Molecular Evolutionary Genetics. Columbia University Press, New York.

PURDY, B. G. AND BAYER, R. J. 1996. Genetic variation in populations of the endemic Achillea millefolium ssp. megacephala from the Athabasca sand dunes and the widespread ssp. lanulosa in western North America. Can. J. Bot., 74, 1138-1146.

RANKER, T. A. 1992a. Genetic diversity of endemic Hawaiian epiphytic ferns: implications for conservation. Selbyana, 13, 131-137.

RANKER, T. A. 1992b. Genetic diversity, mating systems, and interpopulation gene flow in neotropical Hemionitis palmata, L. (Adiantaceae). Heredity, 69, 175-183.

RANKER, T. A. 1994. Evolution of high genetic variability in the rare Hawaiian fern Adenophorus periens and implications for conservation management. Biol. Conserv., 70, 19-24.

SHERMAN-BROYLES, S. L., GIBSON, J. P., HAMRICK, J. L., BUCHER, M. A. AND GIBSON, M. J. 1992. Comparison of allozyme diversity among rare and widespread Rhus species. Syst. Bot., 17, 551-559.

SLATKIN, M. AND BARTON, N. H. 1989. A comparison of three indirect methods for estimating average levels of gene flow. Evolution, 43, 1349-1368.

SOlTIS, D. E., SOLTIS, P. S. AND SMITH, A. R. 1991. Breeding systems of three tree ferns: Alsophila firma (Cyathea- ceae), Cyathea stipularis (Cyatheaceae), and Lophosoria quadripinnata (Lophosoriaceae). Pl. Sp. Biol., 6, 19-26.

SOLTIS, D. E., HAUFLER, C. H., DARROW, D. C. AND GASTONY, G. J. 1983. Starch gel electrophoresis of ferns: a compilation of grinding buffers, gel and electrode buffer, and staining schedules. Am. Fern J., 73, 9-27.

SOLTIS, P. S. AND SOLTIS, D. E. 1987. Population structure and estimates of gene flow in the homosporous fern Polystichum munitum. Evolution, 41, 620-629.

SOLTIS, P. S. AND SOLTIS, D. E. 1990a. Genetic variation within and among populations of ferns. Am. Fern J., 80, $161-172$.

SOlTIS, P. S. AND SOLTIS, D. E. 1990b. Estimation of inbreeding and outcrossing in ferns and fern-allies. $P l$. Sp. Biol., 5, 1-12.

SOLTIS, P. S. AND SOLTIS, D. E. 1991. Genetic variation in endemic and widespread plant species: examples from Saxifragaceae and Polystichum. Aliso, 13, 215-223.

SOlTIS, P. S., SOlTIS, D. E., TUCKER, T. L. AND LANG, F. A. 1992. Allozyme variability is absent in the narrow endemic Bensoniella oregona (Saxifragaceae). Conserv. Biol., 6, 131-134.

TACHIDA, H. AND YOSHIMARU, H. 1996. Genetic diversity in partially selfing populations with the stepping-stone structure. Heredity, 77, 469-475.

TRYON, R. M., JR. 1970. Development and evolution of fern floras of oceanic islands. Biotropica, 2, 76-84.

TSUMURA, Y., TOMARU, N., SUYAMA, N., NA'EIM, M. AND OHBA, K. 1990. Laboratory manual of isozyme analysis. Bull. Tsukuba Univ. For., 6, 63-95 (in Japanese).

WALlER, D. M., O'MALLEY, D. M. AND GAWLER, S. C. 1987 Genetic variation in the extreme endemic Pedicularis furbishiae (Scrophulariaceae). Conserv. Biol., 1, 335-340.

WERTH, C. R. 1991. Isozyme studies on the Dryopteris 'spinulosa' complex, I: the origin of the log fern Dryopteris celsa. Syst. Bot., 14, 446-461.

WERTH, C. R., GUTTMAN, S. I. AND EShBAUgh, W. H. 1985. Electrophoretic evidence of reticulate evolution in the Appalachian Asplenium complex. Syst. Bot., 10, 184-192.

WRIGHT, s. 1951. The genetical structure of populations. Ann. Eugen., 15, 323-354. 